\title{
AIR POLLUTION IN MALAWI
}

\author{
A S Khulumula \\ Malawi Bureau of Standards, \\ PO Box 946, Blantyre, Malawi
}

\section{INTRODUCTION}

Malawi is a landlocked country, some $900 \mathrm{~km}$ long, varying in width from 80 to $160 \mathrm{~km}$ and covering an area of $118,00 \mathrm{~m}^{2}$ of which about $20 \%$ is the lake. It is situated between $9^{\circ}$ and $17^{\circ}$ south of the equator. It is cradled by Mozambique in the south and bordered by Zambia and Tanzania on the west and east, respectively. The population in the 1987 census was just over $7,000,000$. The capital city is Lilongwe, situated in the Central Region and the main commercial and industrial city is Blantyre, situated in the Southern Region. In the Northern Region there is a young city of Mzuzu, while in the south there is the University town of Zomba. About $90 \%$ of the population live in the rural area.

The countryside is marked by highly populated areas in the Southern and Central Regions and sparsely populated areas in the Northern Region. There are rural growth centres in all the three regions that are becoming and checking the influx of people into the urban areas. Manufacturing factories are situated mainly in Blantyre and Lilongwe. However, a number of factories, e.g. producing sugar, ethanol and clinker for cement, are situated right in the rural areas.

Malawi's economy is based on agriculture. Immediately after the attainment of independence in 1964, the Government put out a strong policy that was aimed at strengthening the agricultural base in order to ensure food self-sufficiency. This was, in later years, supplemented by an industrial policy that was aimed at developing the manufacturing sector. As a result of this, the percentage share in GDP by the manufacturing sector has grown since 1965 from $0.5 \%$ to over $15 \%$ in 1982 .

Types of industries range from clothing manufacturing to tea, paints, ethanol, sugar and cement manufacturing.

\section{LEGISLATION AND CONTROL STRUCTURE}

A number of legislations currently in force affect air pollution. One of these is the Public Health Act of the Laws of Malawi (Cap. 34:01) which is the main Act that deals with residential pollution. Part IX of the Act deals with sanitation and housing and ensures that residences and premises are free from any pollution or nuisances liable to be injurious or dangerous to health.

A comprehensive list of actions and situations that are considered to constitute a nuisance is given in the Act. Among these are:

- any street, stream, pool, ditch, sewer, dung pit, refuse pit, slop tank or manure heap so foul or in such a state or so situated or constructed as to be offensive or to be likely to be injurious or dangerous to health;

- any factory or trade premises not kept in a clean state and free from offensive smell arising from any drain or latrine, or not ventilated so as to destroy or render harmless and inoffensive as far as practicable any gases, vapours, dust or other impurities generated, as to be injurious or dangerous to health;

- any factory or trade premises causing or giving rise to smells which are injurious or dangerous to health;

- any machinery sending forth smoke in such quantities or in such a manner as to be offensive or injurious or dangerous to health.

The organisational structure for control consists of the local authorities, i.e. the City of Blantyre, City of Lilongwe, City of Mzuzu and towns in the District Councils. Overall coordination and control is then vested in the hands of the National Environmental Committee (NEC) which has its Secretariat within the Office of the President and Cabinet (OPC). This high level of coordination and control is there to ensure effectiveness in the decision-making process on pollution issues.

\section{LEVELS OF AIR POLLUTION}

The current situation in the country shows that air pollution is not yet a serious problem. This is perhaps due to several factors, among them being: 
(a) types of industries and their sizes;

(b) the ratio of number of cars to human population;

(c) some traditional wood-fire practices in the rural and suburban houses.

However, low levels of air pollution are experienced in areas surrounding some factories where thick fine effluent dust may be seen coming out of chimneys or where anerobic digestion of factory discharges may deliver obnoxious gases to the residential areas.

Monitoring work on these problem areas has been minimal. Any work done has either been due to complaints received from people residing around the factory or other adjacent factories. In each instance, the issues are finally dealt with at the National Environmental Committee level.

The use of wood-fire as a sole source of energy by particularly the suburban and rural populations may seem to pose an air pollution problem. This may be so, particularly when kitchen designs are of the type that do not allow much ventilation. The authorities, however, encourage and advise on kitchen designs which allow maximum ventilation. Again, in this area no work has been done to investigate the level of pollution involved.

The Meteorological Department in Malawi started some work on atmospheric pollution monitoring some few years ago on behalf of the World Meteorological Organization (WMO). Samples of rain precipitation are collected and analysed for elements and particulates. It is hoped that further work in this area may provide a picture of the general atmospheric pollution.
Unlike the situation in industrialised countries, the population of cars in Malawi is relatively low. Emissions from car exhausts do not therefore seem to pose a serious pollution problem. In addition, all motor fuel, except for diesel or gas oil, is a blend of ethanol and regular petrol $(20: 80)$. The use of the blend further reduces this problem.

\section{FUTURE PROSPECTS}

The existence of the central control structure for the environment is a definite indication of the awareness of the importance of checking pollution hazards in the country. A number of things, however, are required in order to ensure a safe future, i.e.:

(a) establishment of explicit laws and regulations on air pollution;

(b) establishment of base data for future use;

(c) establishment of facilities for monitoring purposes.

\section{CONCLUSIONS}

The Malawi Bureau of Standards established a technical committee two years ago on the Environment and Pollution Control. The main task of this committee is to draw up national standards and guidelines on different environmental and pollution issues. Depending on the priority areas, as are identified by the various bodies, in consultation with the TC, national standards will be drawn up. Industrial water effluent is at the top of their list at the moment.

It is also hoped that lessons will be learnt from experiences elsewhere, particularly from highly industrialised nations, which will enable us to maintain our clean air. 